\title{
Avaliação do excesso de casos de tuberculose atribuídos a infecção HIVIAIDS: ensaio preliminar*
}

\author{
Evaluation of the excess of tuberculosis attributable to HIVIAIDS infection
}

\author{
Antonio Ruffino-Netto \\ Departamento de Medicina Social - Faculdade de Medicina de Ribeirāo Preto - Universidade \\ de São Paulo - Ribeirão Petro, SP - Brasit
}

Propže-se realizar um exercício de estimação do risco atribuivel por cento (RA\%) da ocorráncia de casos de tuberculose na vigência da co-infeç̧ão HIV/AIDS. A seguinte formula é apresentada:

$$
R A \%=\frac{p\left[m_{2} r(h R-h)\right]+(1-p)\left[m_{3} r(h R-h)\right]}{p\left[m_{1}+m_{2} r(h R+1-h)\right]+(1-p)\left[m_{3} r(h R+1-h)\right]} \times 100
$$

onde: $p=$ proporçāo infectados pelo BK; $r=$ risco de infecçāo tuberculosa; $h=$ proporçāo de infectados pelo HIV; $m_{1}=$ coeficlente de morbidade reatlvaçăo endógena; $m_{2}=$ coeficientes de morbidade de reinfecçāo exógena; $\mathrm{m}_{3}=$ coeficiente de morbidade tuberculose primária; $\mathrm{R}=$ risco relativo de morbidade entre infectados pelo HIV.

Tuberculose, epidemiologia. Síndrome de Imunodeficiência Adquirida, complicaçôes. Infecçõespor HIV, complicaçōes. Risco.

\section{Introdução}

A co-infecção Tuberculose/HIV/AIDS tem criado problemas de diferentes naturezas que atingem a populaçãoem geral, aos clínicos, epidemiologistas e planejadores da saúde pública.

A tuberculose, endernia caminhando para certo controle em alguns países, "descontrolada" ainda em outros, tem sua tendência alterada frente a ocorrência simultânea da infecçăo pelo HIV. Esta última tem sido apontada como a mais significativa ocorrência que alterou o "equilibrio entre o homem e o bacilo de Kock nos últimos 100 anos, sendo decisiva no risco de adoecimento por tuberculose, seja por reativação endógena ou infecção exógena" (Ministério da Saúde ${ }^{5}$, 1994).

Tem-se assinalado (Styblo ${ }^{14}, 1990$ ) que o impacto da infecção pelo HIV sobre a tuberculose numa determinada populaçāo dependeria dos seguintes elementos:
1- Prevalência da infecção pelo HIV na comunidade e sua tendência.

2- Prevalência da infecção tuberculosa na população entre 15-49 anos.

3- Taxa de morbidade de infecção tuberculosa na população para tuberculose (ativa).

4- Taxa e tendência do risco anual de infeç̧ão tuberculosa.

5- Taxa de deteç̧ão de casos novos, de cura, de abandono, de recaída da tuberculose em pacientes bacilíferos, infectados ou não pelo HIV.

Já se teve oportunidade de apresentar anteriormente modelos epidemiométricos em tuberculose (Ruffino-Netto, 1975, 1976, 1977) onde se estudou a prevalência da doença e alguns modelos especificamente voltados para analisar as equações diferenciais que regem as mudanças de estado nas diferentes categorias classificatórias da tuberculose. Em particular estudou- se os estados "virgem de infecçāo", "infectados" e "doentes". As leis que regem

\footnotetext{
*Trabalho apresentado no Seminário Interprogramas HIV/Tuberculose, Fortaleza, CE, 1994.

Separatas/Reprints: Antonio Ruffino Netto-Departomento de Medicina Social da Faculdade de Medicina de Ribeiräo Preto -

Universidade de São Paulo - Av. Bandeirantes, 3900 - $14049-900$ - Ribeirāo Preto. SP - Brasil

Ediçāo subvencionada pela FAPESP. Processo 95/2290-6.

Recebido em 21.11.1994. Reapresentado em 10.5.1995. Aprovado em 12.6.1995.
} 
tais mudanças são sempre nāo-lineares, e dependendo do número de entradas/saídas dos "compartimentos", resultam em complexidade bastante crescente. $\mathrm{O}$ advento da AIDS, agindo em interação com a tuberculose, veio aumentar esta complexidade.

Decidiu-se, numa primeira aproximação, tentar visualizar/quantificar as colocações feitas por Styblo ${ }^{14}$ através do presente exercício, o qual foi de proposito extremamente simplificado, supondo duas condições: o sistema em equilíbrio e a existência de leis lineares. Tem a função (como exercício) iniciar algumas estimativas de valores.

Modelos mais exaustivos/definitivos deverão ser desenvolvidos posteriormente para que de fato se possa estimar/avaliar a magnitude do impacto da infecção pelo HIV sobre a tuberculose.

\section{Modelo}

Supondo que o percentual $\mathrm{p}$ da população geral (P) já esteja infectada pelo BK, sabe-se que entre esses já infectados alguns evoluem para tuberculose, - doença através de uma reativação endógena. Denominou-se esse coeficiente de adoecimento de $\mathrm{m}_{1}$. Entre os já infectados (P.p) poderão sofrer reinfecções exógenas que dependerá do risco de infecção tuberculosa ( $r$ ) existente na comunidade. Desses reinfectados, evoluem para tuberculose- doença ativa (tuberculose de reinfecção exógena) com um coeficiente que se denominou $\mathrm{m}_{2}$.

A fração da população ainda nāo infectada $P(1-p)$ ficará sujeita ao risco de infecçăo (r). Esses recém-infectados evoluirão para tuberculose primária com um coeficiente que denominou-se de $\mathrm{m}_{3}$ (esquema 1).

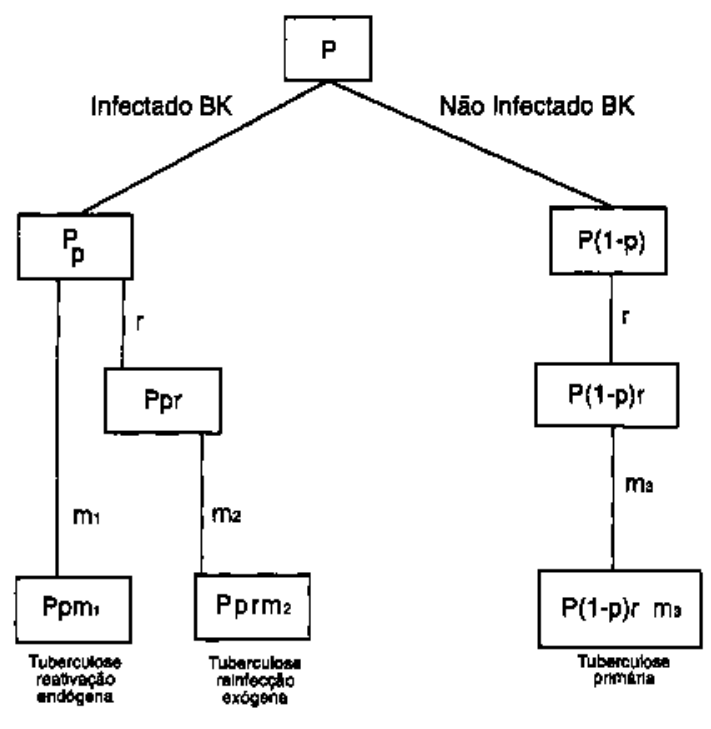

Esquema 1 1992:

Exemplo: situaçăo aproximada para o Brasil, $\mathrm{P}=150.000 .000 ; \mathrm{p}=35 \% ; \mathrm{m}_{1}=0,05 \%$; $\mathrm{m}_{2}=2 \% ; \mathrm{m}_{3}=10 \% ; \mathrm{r}=0,8 \%$

\section{Casos Esperados*}

Tuberculose reativaçāo endógena $=\mathrm{Ppm}_{1}=$ $150.000 .000 \times 0,35 \times 0,0005=26.250$

Tuberculose reinfecção exógena $=\mathrm{Pprm}_{2}=$ $150.000 .000 \times 0,35 \times 0,008 \times 0,02=8.400$

Tuberculose primária $=\mathrm{P}(1-\mathrm{p}) \mathrm{rm}_{3}=$ $150.000 .000 \times 0,65 \times 0,008 \times 0,10=78.000$

Total Geral 112.650

Casos combaciloscopia positiva $112.650 \times 0,55=61.958$

Casos com baciloscopia negativa $112.650 \times 0,45=50.692$

\section{Casos Notiflcados:90.150}

\section{\% de casos notificados: $\mathbf{8 0} \%$}

A ocorrência simultânea da infeç̧ão pelo HIV provoca alteraçóes imunológicas que favoreceria o aparecimento da tuberculose naquelas pessoas já infectadas pelo BK (Rieder e Snider ${ }^{6}, 1986$; Sunderame col. ${ }^{15}, 1986$; Center for Disease Control ${ }^{2}$, 1989; Slutkin e col. ${ }^{12}, 1988$; Chretien ${ }^{3}, 1990$; Watson e Gilli ${ }^{16}$, 1990; WHO ${ }^{17}, 1991$; De Cock e col. ${ }^{4}$, 1992).

Estudos prospectivos e/ou retrospectivos têm estimado o risco relativo ( $R$ ) do desenvolvimento da tuberculose entre os co-infectados pelo BK/HIV (Selwyn e col. ${ }^{11}$, 1989; Braun e col. ${ }^{1}, 1991$ ).

Assim, na suposição de que na população dos já infectados pelo $\mathrm{BK}$ e reinfectados (Ppr) do esquema 1 , a fraçāo $h$ esteja também infectada pelo HIV, e esta evolua para a tuberculose doença ativa com um coeficiente $\left(m_{2}, R\right)$. Da mesma forma os não infectados $\mathrm{P}(1-\mathrm{p})$ poderāo se infectar. Portanto, tem-se 0 esquema 2 .

O risco atribuível por cento (RA\%) seria dado pela expressāo:

$$
R A \%=\frac{l e-10}{l e} \times 100
$$

onde:

$I \boldsymbol{e}=\boldsymbol{\epsilon}$ a incidência de tuberculose ativa no grupo exposto à co-infecção $\mathrm{BK} / \mathrm{HIV}$

$I o=$ é a incidência de tuberculose ativa no grupo infectado apenas pelo BK

*Tais cálculos são efetuados com estimativas para $p, m_{1}, m_{2}, m_{3}$ e r obtidas no Curso Nacional de Pneumologia Sanitaria. Ministerio da Saude - 1992. 


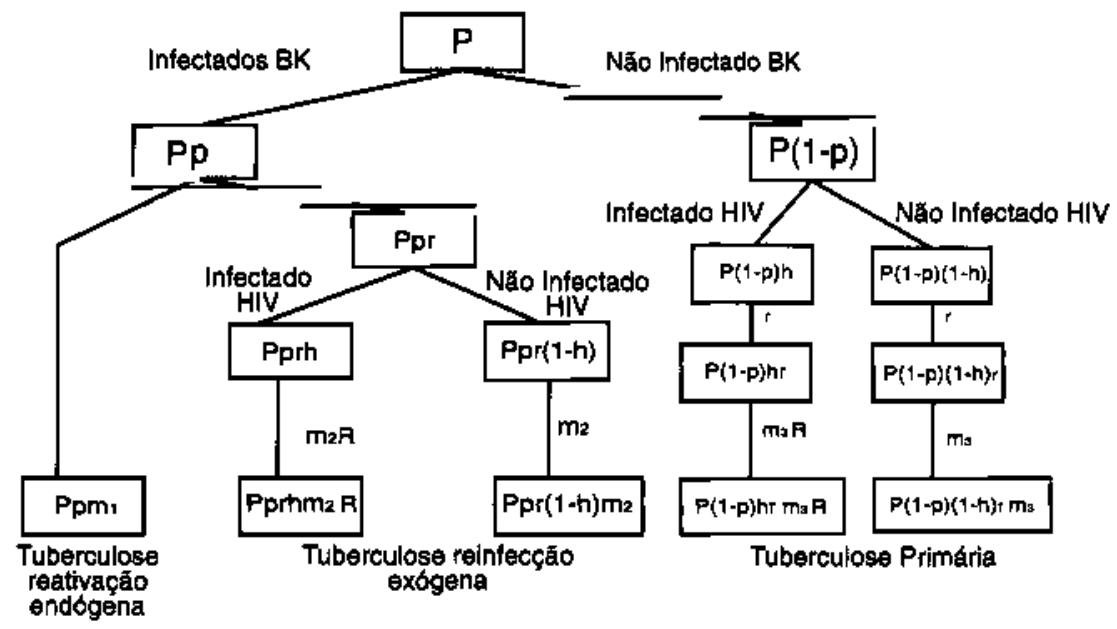

Esquema 2

ou seja:

$\boldsymbol{I} \boldsymbol{e}=\mathrm{Ppm}_{1}+\mathrm{Pprhm}_{2} \mathrm{R}+\mathrm{Ppr}(1-\mathrm{h}) \mathrm{m}_{2}+\mathrm{P}(1-\mathrm{p}) \mathrm{rh} \mathrm{\textrm {m } _ { 3 }}$

$R+P(1-p) r(1-h) m_{3}$

$I o=\mathrm{Ppm}_{1}+\mathrm{Pprm}_{2}+\mathrm{P}(1-\mathrm{p}) \mathrm{rm}_{3}$

e o excesso de casos de tuberculose atribuído a infecção pelo HIV seria dada pela expressão final:

$$
R A \%=\frac{p\left[m_{2} r(h R-h)\right]+(1-p)\left[m_{3} r(h R-h)\right]}{p\left[m_{1}+m_{2} r(h R+1-h)\right]+(1-p)\left[m_{3} r(h R+1-h)\right]} \times 100
$$

que demonstra os elementos $1,2,3$ e 4 retro referidos, levantados por Styblo ${ }^{14}, 1990$.

Assim, por exemplo imaginando a situação $\mathrm{p}=35 \%$

$\mathrm{m}_{1}=0,05 \% ; \mathrm{m}_{2}=2 \% ; \mathrm{m}_{3}=10 \% ; \mathrm{r}=0,8 \%$; $\mathrm{h}=2 \% ; \mathrm{R}=15$

O excesso de casos de tuberculose devido a infecção HIV, nessa situação epidemiológica, seria estimado em $17,7 \% *$.

\section{Conclusăo}

Um exercício foi feito no sentido de vizualizar/ quantificar os elementos referidos na Introdução. Espera-se que modelos mais completos devam ser desenvolvidos, encontrando-se as equaçōes diferenciais respectivas para completar este ensaio e efetivamente avaliar o risco atribuível.

\section{Referênclas Bibliográficas}

1. BRAUN, M. M.; BADI, N.; RYDER. R. W. A retrospective cohort study of risk of the of tuberculosis arnong women of childbearing age with HIV infection in Zaire. Am.

- Para simulação utilizou-se $R=15$ baseado nas referéncias 1,1$]$ $e \mathrm{~h}=2$ baseado em estimativas preliminares em alguns grupos no Rio de Janeiro - 1994.
Rev. Resp. Dis, 143: 501-4, 1991.

2. CENTERS FOR DISEASE CONTROL. Tuberculosis and human immunodeficiency virus infection; recomendations of The Advisory Committee for the Elimination of Tuberculosis (ACET), MMWR, 38 (14): 236-50, 1989.

3. CHRETIEN, J. Tuberculosis y VHI: el dúo maldito. Bol. Union Int. Tuberc., 65: 27-30, 1990.

4. DE COCK K. M.; SORO, B.; COULIBALY, I. M.; LUCAS, S. B. Tuberculosis and HIV infection in Sub-Saharan Africa. JAMA, 268: 1581-7, 1992.

5. MINISTÉRIO DA SAÚDE. Secretaria de Assistência à Saúde. Programa Nacional de Doenças Sexualmente Transmissíveis/AIDS. Co-Infecçđo TB/HIV/AIDS. Brasilia, 1994.

6. RIEDER, H. L. \& SINIDER Jr, D. E. Tuberculosis and acquired immunodeficiency syndrome. Chest, 90: 469$70,1986$.

7. RUFFINO-NETTO, A. Epidemiologia da tuberculose: estudo de alguns aspectos ligados a modelos de prevençăo, diagnóstico e modelos epidemiológicos. Ribeirăo Preto, 1975. [Tese de Livre-Docência -Faculdade de Medicina de Ribeirăo Preto da USP].

8. RUFFINO-NETTO. A. Cálculo do risco de infeç̧ăo tuberculosa levando em consideraçăo pessoas perdioas de seguimento. Rev. Div. Nac. Tuberc., 20: 383-90, 1976.

9. RUFFINO-NETTO, A. Modelos epidemiométricos em tuberculose: definição de "estados" e risco de infeç̧ão. Rev. Saúde Pública, 11: 188-98, 1977.

10. RUFFINO-NETTO, A. Estudo da prevalência da tuberculose. Ciênc. e Cult., 29: 1429-33, 1977.

11. SELWYN, P. A.; HARTEL, D.; LEWIS, V. A. A prospective study of risk of tuberculosis among intravenous drug users with human immunodeficiency virus infection. $N$. Engl. J. Med., 320: 545-50, 1989.

12. SLUTKIN, G.; LEOWSKI, J.; MANN, J. Efectos de la epidemia de SIDA sobre la situacion de la tuberculosis y sobre los programas de control de la tuberculosis. Bol. Union Int. Tuberc., 63 (2): 22-5, 1988.

13. STYBLO. K. Impacto potencial del SIDA sobre la situación y la tuberculosis en los prises desarrollados y en desarrollo. Bol. Union Int. Tuberc, 63 (2):26-29, 1988.

14. STYBLO, K. Aspectos sobre la tuberculosis y la infeccion VIH a nível mundial. Bol. Union Int. Tuberc., 65 (1): 30-5, 1990.

15. SUNDERAM, G.; McDONALD, R. L.; MANIATIS, T.; 
OLESKE, J.; KAPILA, R.; REICHMAN, L. B. Tuberculosis as a manifestation of the Acquired Immunodeficiency Syndrome (AIDS). JAMA, 256: 362-6, 1986.

16. WATSON, J.M. \& GILLI,O.N. HIV infection and tuberculosis: consider tuberculosis in patients with AIDS. BMJ (London) 360: 63-5, 1990.

17. WORLD HEALTH ORGANIZATION. Turbeculosis and HIV infection. Wkly Epidemiol. Rec., 4: 19-23, 1991.

\section{Abstract}

An exercise for the estimation of the percentage risk of cases of tuberculosis attributable to co-infection HIV/AIDS, using the following formula, is propounded:

$$
R A \%=\frac{p\left[m_{2} r(h R-h)\right]+(1-p)\left[m_{3} r(h R-h)\right]}{p\left[m_{1}+m_{2} r(h R+1-h)\right]+(1-p)\left[m_{3} r(h R+1-h)\right]} \times 100
$$

where: $p=$ proportion of $B K$ infected, $r=r i s k$ of tuberculosis infection, $h=$ proportion of persons infected with HIV, $m_{1}=$ breakdown rate of endogenous tuberculosis, $\boldsymbol{m}_{2}=$ breakdown rate of exogenous tuberculosis, $\boldsymbol{m}_{\mathrm{s}}=$ breakdown rate of primary tuberculosis, $R=$ relative risk of moridity among persons infected with HIV.

Tuberculosis, epidemiology. Acquired immunodeficiency syndrome, complication. Risk. 